\title{
DOR E PRAZER NA PRÁTICA MUSICAL: As emoções, sentimentos e o estado de flow na prática de músicos instrumentistas.
}

\author{
Rodrigo Alcântara de Souza, UFAM \\ Claudia Mont'Alvão, PUC-Rio
}

Resumo: É grande o número de músicos que sofre com dores, desconfortos e lesões decorrentes da atividade musical, no entanto o tema ainda é pouco explorado e existem muitas lacunas a serem preenchidas para que a prática musical seja menos prejudicial à saúde dos praticantes. Apresenta-se aqui uma pesquisa de caráter exploratório realizada com 39 músicos da cidade de Manaus dando ênfase às questões emocionais envolvidas na prática e sobre como elas podem interferir na percepção dos constrangimentos. Uma questão central é a prática musical poder ser favorável à ocorrência do estado de flow (CSIKSZENTMIHALYI, 1997), o que justificaria o fato de muitos músicos não perceberem as dores e desconfortos durante a execução das atividades. Os resultados apontam que a prática musical, dentro dessa amostra, apresenta características similares às encontradas nas ocorrências do estado de flow e descrevem a importância das questões emocionais nessa prática.

Palavras-chave: Prática Musical, Ergodesign, Constrangimentos, Estado de Flow, Emoções e sentimentos.

\begin{abstract}
A great number of musicians suffer from pain, discomfort and injury arising out of musical activity, however the issue is still little explored and there are many gaps to be filled for the musical practice become less harmful to the practitioners. Here is presented an exploratory research conducted with 39 musicians in the city of Manaus emphasizing the emotional issues involved in the practice and how they can affect the perception of constraints. A major issue is that musical practice may be favorable to the occurrence of a state of flow (Csikszentmihalyi, 1997), which could explain the fact that many musicians do not realize the pain and discomfort during the execution of the activities. The results show that musical practice, within this sample, shows similar characteristics to those found in the occurrence of flow state and describe the importance of emotional issues in this practice.
\end{abstract}

Keywords: Musical Practice, Ergodesign, Constraints, State of Flow, Emotions and feelings. 


\section{INTRODUÇÃO}

É comum a ideia de que a atividade musical por estar muito ligada a questões emocionais e de expressividade, é um trabalho bem diferente dos outros. Dessa forma, tem-se a noção equivocada de que ao músico é necessário apenas talento e de que o fazer musical configura-se como um ato de lazer e exclusivamente prazeroso. Essa visão, no entanto, não contempla as reais atividades desenvolvidas pelos músicos, que compreendem estudos e treinos constantes, longos e cansativos ensaios e uma grande rotina de apresentações.

A exaustiva carga de trabalho, os movimentos repetitivos e instrumentos e ambientes cujo projeto não condiz com determinados aspectos das atividades a serem desenvolvidas e com as capacidades dos usuários, acabam por prejudicar a saúde dos músicos. Além disso, Costa (2003) relata duas culturas presentes no meio musical: a cultura do silêncio e a cultura da dedicação que contribuem para que esses problemas de saúde sejam bastante recorrentes no meio.

Observa-se há algumas décadas um crescente interesse de pesquisadores pelo tema, no entanto ele ainda tem pouco destaque e, muitas das vezes, nem os próprios músicos lhe dão importância.

\section{PRÁTICA REAL DOS MÚSICOS EM CONTRAPOSIÇÃO À NOÇÃO ROMANTIZADA}

Quando se fala em artista, a maior parte das pessoas tem uma noção equivocada sobre o que seria esta ocupação e sobre suas reais práticas, a começar pelo fato de não ser compreendida como uma profissão como as outras, mas como mero divertimento, lazer ou hobby. O equívoco é tamanho que muitos artistas, ainda que tenham uma vivência prática da rotina de trabalho e suas dificuldades, também têm uma visão distorcida, considerando suas próprias práticas como algo misterioso, fruto de um dom e inspiração divinos. De modo geral, tanto leigos quanto artistas, profissionais ou amadores, compartilham em menor ou maior grau desse tipo de pensamento. Esta noção (romantizada) da arte como algo superior e do artista como uma pessoa diferenciada está enraizada na cultura ocidental atual e é fruto de vários processos históricos analisados pela sociologia da arte e descritos em SOUZA e MONT'ALVÃO (2012).

O trabalho musical possui uma rotina regular de atividades que possibilitam os processos de composição, execução e audição musical. Ainda que aparentemente tenha um conteúdo emocional e lúdico maior do que outros tipos de trabalho, o rigor das atividades desempenhadas o torna tão cansativo quanto qualquer outro. Do mesmo modo, as aspirações dos músicos não se encontram somente no que se refere a fazer uma música de qualidade, ou a atingir uma "elevação espiritual". Já no século XVII, Monteverdi (BLANNING, 2011) revelava as coisas que o músico desejava e deseja: dinheiro, estabilidade, controle sobre sua criação e respeito. Ou seja, um trabalhador comum, com aspirações de trabalhadores comuns.

Med $(2004$, p.28;88) contextualiza as reais atividades dos músicos:

O músico profissional precisa treinar diariamente algumas horas. (...) Deve ensaiar com outros músicos, estudar os tratados musicais, manuais, biografias e literatura musical. (...) Necessita atualizar-se sempre, pois a música e a técnica interpretativa evoluem constantemente. (...) Ou o músico se adapta a essa situação, ou fica fora do mercado. (...) Para manter um razoável nível de vida, o músico profissional no Brasil precisa "se virar", isto é, ter várias atividades musicais ao mesmo tempo. Por exemplo: de manhã, trabalha na orquestra; à tarde dá aulas ou ensaia em conjuntos; à noite, 
toca em shows, em casas noturnas ou grava discos em estúdio; às sextasfeiras, toca em um ou até mais casamentos; aos sábados, toca em bailes; e, aos domingos, descansa tocando na igreja.

A partir da descrição estabelecida por alguns autores (MED, 2004; COSTA, 2003; etc.) e das observações acerca do cotidiano desses trabalhadores, pode-se sintetizar os principais pontos que diferenciam a noção romantizada e a noção real a respeito do trabalho dos músicos, conforme apresentado no quadro 1 , a seguir:

Quadro 1 - Noção Romantizada x Noção Real das atividades do músico

\begin{tabular}{|l|l|}
\hline \multicolumn{1}{|c|}{ Noção Romantizada } & \multicolumn{1}{c|}{ Noção Real } \\
\hline $\begin{array}{l}\text { - O trabalho do músico se resume ao } \\
\text { desempenhado no palco, durante as } \\
\text { apresentações; }\end{array}$ & $\begin{array}{l}\text { - O trabalho do músico envolve, além das } \\
\text { apresentações, muitas horas de estudo, ensaios e } \\
\text { algumas vezes até atividades administrativas; }\end{array}$ \\
\hline $\begin{array}{l}\text { - A atividade do músico não é um trabalho, } \\
\text { mas uma atividade de lazer; }\end{array}$ & $\begin{array}{l}\text { - Existem músicos que tocam só por lazer, } \\
\text { entretanto, muitos têm na atividade musical o seu } \\
\text { trabalho e dependem dela para o seu sustento. }\end{array}$ \\
\hline $\begin{array}{l}\text { - O trabalho do músico é muito gratificante } \\
\text { e eles sempre estão se divertindo enquanto } \\
\text { tocam; }\end{array}$ & $\begin{array}{l}\text { - Os músicos muitas vezes têm que tocar músicas } \\
\text { que não gostam ou em situações que não lhe } \\
\text { deixam confortáveis, sem contar as condições de } \\
\text { trabalho que podem tornar o exercício da } \\
\text { profissão um sacrifício; }\end{array}$ \\
\hline $\begin{array}{l}\text { - Os músicos já nascem com um talento } \\
\text { especial para esse tipo de atividade e é esse } \\
\text { talento aliado à inspiração que faz com que } \\
\text { surjam grandes obras/apresentações } \\
\text { musicais; }\end{array}$ & $\begin{array}{l}\text { - De modo geral a regularidade e a carga diária de } \\
\text { estudos/treino são pré-requisitos para o sucesso } \\
\text { na carreira do músico e é isso que torna possível } \\
\text { obras e apresentações de qualidade }\end{array}$ \\
\hline $\begin{array}{l}\text { - O trabalho do músico é um trabalho } \\
\text { individual }\end{array}$ & $\begin{array}{l}\text { - Praticamente toda a música ocidental consiste } \\
\text { em uma interação trilateral entre criadores, } \\
\text { intérpretes e públicos. Além disso, muitos outros } \\
\text { profissionais são envolvidos para que a atividade } \\
\text { do músico se torne possível. }\end{array}$ \\
\hline
\end{tabular}

Pode-se finalizar a questão com as palavras de Costa (2003, p.36): “As exigências de formação e de performance somam-se à realidade do mercado de trabalho, colocando à margem a visão romantizada do músico genial e sua dedicação em limiares sobre-humanos." Ou seja, nada de talento inato e inspiração como determinante da criatividade artística. A música é trabalho e trabalho árduo.

\section{PROBLEMAS DE SAÚdE EM MÚSICOS}

As atividades desenvolvidas pelos músicos muitas vezes prejudicam a saúde desses trabalhadores. Os problemas variam de pequenas dores ou desconfortos até lesões que impedem o músico de continuar exercendo a profissão. No entanto, apesar da gravidade, o tema é frequentemente negligenciado pelos próprios músicos e por outras pessoas envolvidas nessas atividades. Se por um lado o tema é pouco explorado e divulgado, por outro, o problema é bem antigo. Um dos registros mais antigos é feito por Ramazzini (apud FRANK \& VON MÜLHEN, 2007) que já em 1718 alertava para as queixas de artistas e artesãos, incluindo músicos. Outro registro (DAUM, 1988), é feito em 1839 pelo pianista e compositor Robert Schumann que descreve um distúrbio osteomuscular relacionado à prática musical, relatando que alguns dedos haviam se tornado fracos por conta do uso excessivo a ponto de ele mal poder usá-los. 
Existem registros antigos também da preocupação de outros profissionais com a saúde dos músicos. Em 1887, Poore (1887) publica no The British Medical Journal um artigo a respeito do tema. Neste artigo, o médico apresenta o caso de 21 pianistas que tinham problemas em músculos e tendões por conta do excesso de uso e que os impediam de continuar tocando. De acordo com Dommerholt (2009), a essa publicação seguiram-se outras tratando de violinistas (1890) e cornetistas (1893) até que o primeiro livro de medicina relacionado a artes foi publicado em 1932.

Mesmo após essas publicações iniciais, o tema continuou tendo pouca notoriedade até a década de 1980 (BRANDFONBRENER, 2003; DOMMERHOLT, 2009), quando passaram a ser feitos vários levantamentos cujos resultados tem sido consistentes e confirmam a impressão de que a taxa de ocorrência desse tipo de problema entre músicos é significativa. Um dos mais notáveis desses levantamentos foi publicado em 1988 nos Estados Unidos pela ICSOM (International Conference of Symphony Orchestra Musicians) segundo o qual 76\% dos 2212 respondentes, relataram já ter passado por algum problema dessa natureza, afetando de modo considerável as suas habilidades de execução musical. A gravidade do problema vem sendo confirmada por várias outras pesquisas conforme pode ser visto na compilação feita por Frank e Von Mühlen (2007) apresentada no quadro 2, a seguir:

Quadro 2 - Compilação de pesquisas sobre a ocorrência de dores em músicos

\begin{tabular}{|c|c|c|c|c|c|c|}
\hline Autores & Ano & Público-alvo & $\begin{array}{l}\text { Taxa de } \\
\text { Prevalência }\end{array}$ & $\mathrm{N}$ & $\begin{array}{l}\text { Preva- } \\
\text { lência }\end{array}$ & $\begin{array}{l}\text { Obser- } \\
\text { vação }\end{array}$ \\
\hline Fry & 1986 & Mús. de orquestra & Tempo de vida & 485 & $42 \%$ & \\
\hline $\begin{array}{l}\text { Caldron e } \\
\text { Calabrese }\end{array}$ & 1986 & $\begin{array}{l}\text { Profissionais, amadores, } \\
\text { professores e } \\
\text { universitários }\end{array}$ & Tempo de vida & 250 & $38,6 \%$ & $\begin{array}{l}\text { Sem } \\
\text { sopros }\end{array}$ \\
\hline Lockwook & 1988 & Menores de 18 anos & Tempo de vida & 113 & $49 \%$ & \\
\hline $\begin{array}{l}\text { Fishbein e } \\
\text { Middelstadt }\end{array}$ & 1989 & $\begin{array}{l}\text { Músicos de orquestra } \\
\text { profissionais }\end{array}$ & Tempo de vida & 2212 & $76 \%$ & \\
\hline $\begin{array}{l}\text { Mathews e } \\
\text { Mathews }\end{array}$ & 1993 & $\begin{array}{l}\text { Músicos de orquestra } \\
\text { profissionais }\end{array}$ & Pontual & 29 & $55 \%$ & \\
\hline $\begin{array}{l}\text { Larsson et } \\
\text { al. }\end{array}$ & 1993 & $\begin{array}{l}\text { Profissionais e } \\
\text { universitários }\end{array}$ & Tempo de vida & 660 & $67 \%$ & \\
\hline Shoup & 1995 & Menores de 18 anos & Tempo de vida & 425 & $33,2 \%$ & \\
\hline Blum & 1995 & $\begin{array}{l}\text { Músicos de orquestra } \\
\text { profissionais }\end{array}$ & Tempo de vida & 1432 & $86,3 \%$ & Só cordas \\
\hline $\begin{array}{l}\text { Salmon e } \\
\text { Shook }\end{array}$ & 1995 & $\begin{array}{l}\text { Profissionais, professores } \\
\text { e universitários }\end{array}$ & Tempo de vida & 154 & $29 \%$ & \\
\hline $\begin{array}{l}\text { Zetterberg e } \\
\text { Blacklund }\end{array}$ & 1998 & Universitários & Anual & 227 & $38,8 \%$ & \\
\hline $\begin{array}{l}\text { Yeung e } \\
\text { Chan }\end{array}$ & 1999 & $\begin{array}{l}\text { Músicos de orquestra } \\
\text { profissionais }\end{array}$ & Anual & 39 & $64,1 \%$ & \\
\hline $\begin{array}{l}\text { Shields e } \\
\text { Dockwell }\end{array}$ & 2000 & Universitários & Tempo de vida & 159 & $25,8 \%$ & Só piano \\
\hline Guptill et al & 2000 & Universitários & Tempo de vida & 108 & $87,7 \%$ & \\
\hline Rigg et al & 2003 & $\begin{array}{l}\text { Profissionais, amadores e } \\
\text { universitários }\end{array}$ & Anual & 261 & $61,3 \%$ & Só violão \\
\hline Kaneko et al & 2005 & $\begin{array}{l}\text { Músicos de orquestra } \\
\text { profissionais }\end{array}$ & Pontual & 241 & $68 \%$ & \\
\hline
\end{tabular}

Fonte: Frank e Von Mühlen (2007) 
É importante observar, no entanto, que as pesquisas desenvolvidas não se resumem a levantamentos quantitativos. Alguns exemplos: Zaza et al. (1998) apresenta uma pesquisa que objetivou descobrir como os músicos percebem problemas osteomusculares relacionados à prática musical e como os distinguem de dores consideradas normais; Chan et al. (2000) trata de um experimento que buscou comparar o nível de fadiga muscular em músicos medidos através de exames e a fadiga percebida por esses músicos; Daum (1988), Cockey et al. (apud QUARRIER, 1993) e Subtil (2009) apresentam relações de cuidados a serem tomados pelos músicos a fim de evitar problemas de saúde relacionados à prática. Uma análise das publicações a respeito do tema permite perceber a existência de muitas lacunas e a diversidade de enfoques que podem ser dados às pesquisas. Fato é que, conforme as palavras de Brandfonbrener (2003), ao longo das últimas décadas os médicos (e demais pesquisadores) têm tido conhecimento de algo que os músicos já sabiam há muito tempo: tocar um instrumento musical pode ser doloroso e prejudicial.

\section{CULTURA DA DEDICAÇÃO E DO SILÊNCIO}

De acordo com Quarrier (1993), muitos estudos tem investigado a prevalência de distúrbios relacionados à prática musical. No entanto, a confiabilidade dos estudos é por vezes questionada por conta da relutância dos músicos em responder. A hipótese de vários pesquisadores é que um número significante de músicos não admite que tenham tido reais problemas ou podem relutar na divulgação pública destes problemas mesmo com garantias de confidencialidade. Muitas vezes, o músico só admite a existência de tais problemas quando são realmente muito graves, de forma que provavelmente ocorrem muito mais lesões do que as que são relatadas.

Costa (2003) relata duas culturas presentes no meio musical que podem ser as responsáveis por esse comportamento de não admitir publicamente ou para si mesmo as dores e desconfortos:

- A cultura do silêncio, onde o músico não expõe seus desconfortos pela possibilidade de perdas econômicas e de oportunidades;

- A cultura da dedicação, com a ideia de que as dores fazem parte da profissão e que, por isso, seria normal senti-las.

Esta última está relacionada à expressão "no pain, no gain", sobre a qual Brandfonbrener (2003) fala que os músicos muitas vezes são aconselhados dessa forma, na busca de habilidade e excelência de execução, e que, ainda que esses conselhos possam ser bem intencionados, condutas deste tipo, quando levadas ao pé da letra, ao invés de contribuírem para o sucesso musical, põem os músicos em risco de desvios na sua carreira e até encerramento da mesma. No entanto, este conhecimento não parece chegar a todos os músicos, de modo que, conforme Costa (2003 p.36), é observada essa "associação entre a profissão de músico e a ideia da inevitabilidade do aparecimento de dores ao longo da carreira". Assim, intensifica-se a tendência de tocar mesmo com a ocorrência de dores.

\section{EMOÇÕES, PRAZER E ESTADO DE FLOW}

É comum que se ache normal no meio musical a presença dessas dores, como parte de um trabalho que está sendo bem desenvolvido. Também é comum situações em que os músicos chegam mesmo a não sentir as dores ou a senti-las de modo reduzido, por conta do seu envolvimento com a atividade que estão desenvolvendo. 
Desta forma, é importante que se dê atenção às relações emocionais ligadas a essa prática, sobretudo à dicotomia prazer e dor. De acordo com Damásio (2004), os sentimentos de dor ou prazer são os alicerces da mente e, por mais que às vezes passem despercebidos, estão sempre presentes e só descansam quando chega o sono.

De acordo com Csikszentmihalyi (1997), no dia-a-dia, é raro que os conteúdos das experiências estejam em sincronia uns com os outros. Quando se está trabalhando, por exemplo, a atenção do indivíduo pode estar focada porque o seu chefe lhe deu uma tarefa que exige um uso intenso do intelecto, entretanto, ele pode se distrair facilmente por conta de outros pensamentos, emoções e intenções que vêm à mente e logo depois desaparecem, fazendo com que a atenção se disperse. Essas situações são muito comuns e a experiência cotidiana está cheia delas.

Existe, no entanto, algumas outras situações em que a pessoa se mantém completamente envolvida no que está fazendo, de modo que o que ela sente, deseja e pensa está em completa harmonia. O que acontece nessas situações é o que Csikszentmihalyi (1997) chama de estado de flow, ou simplesmente flow. Nas palavras do próprio Csikszentmihalyi à revista Wired (1996) o estado de flow é:

Estar completamente envolvido em uma atividade para o seu próprio bem. O ego desaparece. O tempo voa. Cada ação, movimento e pensamento segue inevitavelmente o anterior, como tocar jazz. Todo o seu ser está envolvido e você está usando suas habilidades ao máximo.

Trabalha-se nessa pesquisa com a ideia de que o flow esteja presente na prática musical, o que justificaria, ao menos em parte, o comportamento de instrumentistas de não se queixarem de dores e desconfortos provenientes das suas atividades.

Quando o flow ocorre, a consciência está cheia de experiências e essas estão em harmonia entre si. Esse estado tende a ocorrer quando o indivíduo enfrenta um conjunto claro de metas que exigem respostas apropriadas e recebe um feedback imediato.. Durante o flow, a noção de tempo se torna distorcida e a pessoa se sente mais forte do que normalmente. Além disso, o flow tende a ocorrer quando o indivíduo enfrenta altos níveis de desafio, coerente com um alto nível de habilidades do mesmo, conforme mostra a figura 1 , a seguir.

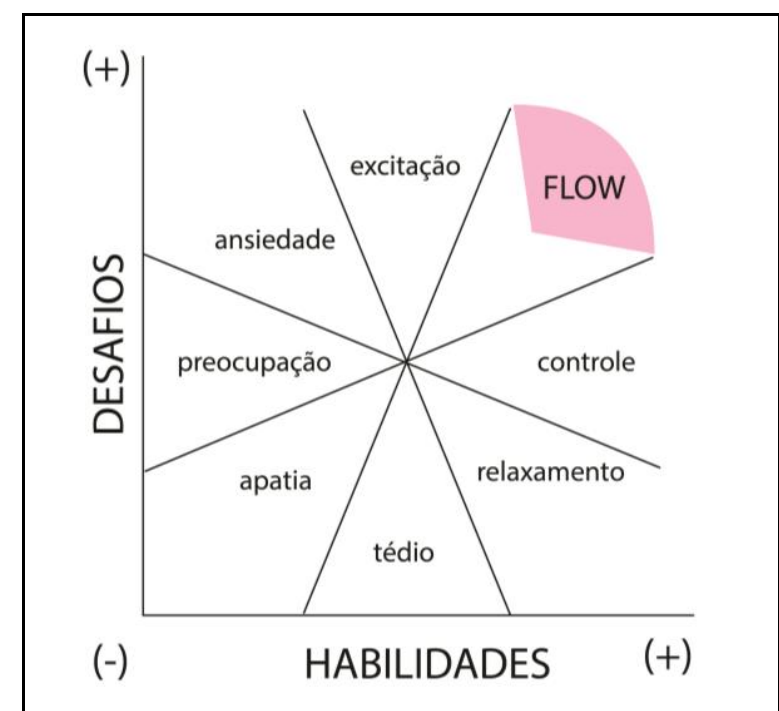

Figura 11- Determinação de uma experiência ótima, ou flow, de acordo com as relações entre desafios e habilidades.

Fonte: adaptado de Csikszentmihalyi (1997) 
Csikszentmihalyi (1997) sintetiza que quando as metas são claras, o feedback é relevante e os desafios e as habilidades estão em equilíbrio, a atenção torna-se ordenada e completamente investida. A grande demanda de energia psíquica faz com que uma pessoa em estado de flow fique inteiramente focada, sem que haja espaço na sua consciência para pensamentos que a distraiam ou sentimentos irrelevantes.

É importante, no entanto, que o flow não seja confundido com felicidade. Quando as pessoas estão em estado de flow não estão felizes, uma vez que a experiência da felicidade exige que elas se foquem em seu estado interno, o que tiraria a atenção sobre a atividade que estão executando. Csikszentmihalyi (1997) fala que um cirurgião não pode sentir felicidade durante uma operação, nem um músico enquanto executa uma música desafiadora, mas somente depois que a atividade foi completada e se tem tempo livre para refletir sobre esta atividade e sentir-se feliz em retrospecto.

O autor (CSIKSZENTMIHALYI, 1997) fala ainda que, aparentemente, quando a energia psíquica não está comprometida com uma tarefa definida é mais fácil perceber as coisas que estão erradas no corpo, como a dor, por exemplo. É por isso que jogadores de xadrez podem jogar por horas sem sentir fome ou dores de cabeça e atletas em competição podem ignorar dores e fadiga até que o evento termine. Quando a atenção está focada em algo, pequenas dores não são registradas na consciência. Damásio (2004, pg.123) descreve situação semelhante quando os mapas cerebrais - e os sentimentos consequentemente - não correspondem ao real estado do corpo: "Quando tentamos fugir de um determinado perigo é uma ótima ideia não sentir a dor que sobreviria no caso de termos sido feridos pela fonte de perigo ou no caso de o próprio ato da fuga causar ferimentos".

A explicação para isso é a de que "o cérebro consegue eliminar de forma eficaz a transmissão de sinais cujo mapeamento levaria à experiência da dor", o que também ocorre, por exemplo, com soldados em combate e mulheres em trabalho de parto. Essa interferência do cérebro equivale a tomar uma alta dose de aspirina ou morfina ou ainda uma anestesia local. Damásio (2004, p.124) fala também que algo similar acontece com pessoas acostumadas a falar em público, como atores, por exemplo, que são obrigadas a atuar mesmo quando estão doentes e notam "o estranho e súbito desaparecimento dos sintomas físicos no momento preciso em que entram no palco".

\section{METOdOLOGIA}

A pesquisa caracteriza-se como exploratória, uma vez que desenvolve e esclarece questões sobre a relação entre os constrangimentos sofridos pelos músicos no desempenho de suas atividades e as questões emocionais envolvidas nessa prática através do levantamento de opiniões, atitudes e crenças desse grupo de indivíduos. Para atingir o objetivo geral da pesquisa de "compreender como os músicos percebem os problemas/constrangimentos ergonômicos provenientes da prática musical e como relacionam essa percepção com as questões emocionais presentes nessa prática", elaborou-se um instrumento de coleta de dados denominado "Instrumento de Levantamento de Dados Objetivos e Subjetivos das Atividades do Músico - LeDOS Music". O instrumento encontra-se estruturado em 4 partes:

Parte 1 - Questionário auto aplicado, sob orientação do pesquisador, com perguntas fechadas e abertas abordando aspectos gerais da prática musical e a incidência de dores e desconfortos, entre outros temas; 
Parte 2 - Uma espécie de card sorting, composto por 24 cartões com palavras descrevendo emoções e sentimentos sentidos durante a prática musical. Os respondentes devem separar os cartões que correspondem ao que sentem durante a prática musical e ordená-los em relação à frequência com que sentem;

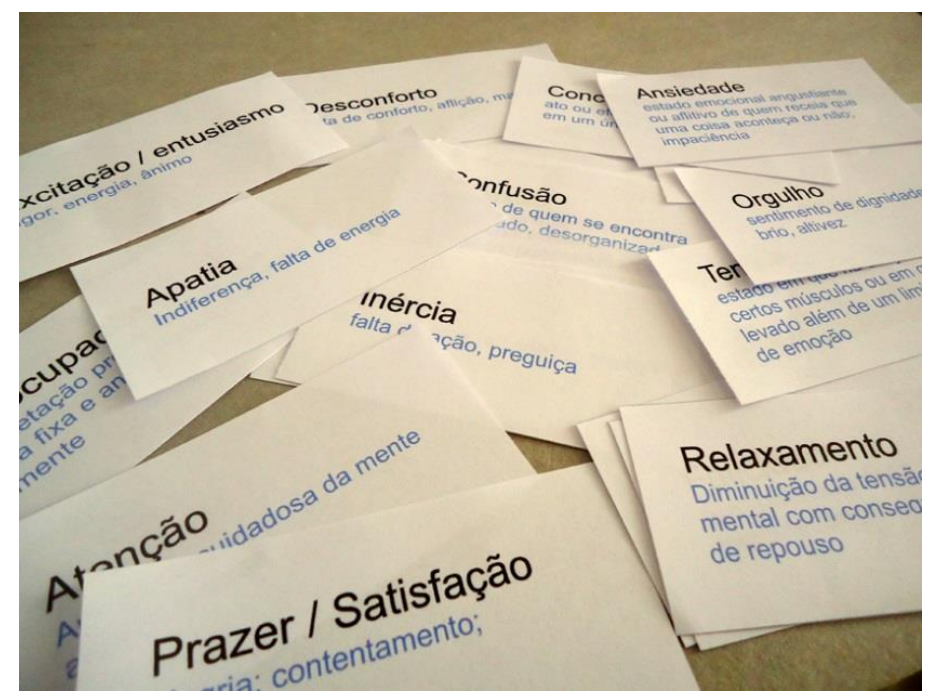

Figura 22- Cartões utilizados na segunda parte do instrumento.

Parte 3 - Escala de Avaliação de Likert apresentando questões a respeito do estado de flow (CSIKSZENTMIHALYI, 1997) e da cultura da dedicação (COSTA, 2003);

Parte 4 - Entrevista semiestruturada abordando constrangimentos presentes na prática musical e a influência dos fatores emocionais dentro desse contexto, explorando de maneira mais subjetiva a opinião e experiências dos respondentes.

\section{COLETA DE DADOS E RESULTADOS}

A amostragem utilizada na coleta de dados foi do tipo não probabilística por acessibilidade ou por conveniência na qual, de acordo com Gil (2010), são selecionados os elementos a que se tem acesso, admitindo que estes possam, de alguma forma, representar o universo estudado. Em algumas situações fez-se uso também da amostragem bola de neve ou por indicação, na qual os respondentes indicam outros respondentes potenciais (HAIR JR. ,et al, 2010).

Toda a coleta foi realizada entre os meses de janeiro e agosto de $2012 \mathrm{com}$ músicos profissionais, amadores e biprofissionais (que também exercem outra profissão) da cidade de Manaus. Os respondentes eram abordados através de contato prévio por telefone ou e-mail. No momento do encontro eram esclarecidos os pontos a serem tratados na coleta de dados e apresentado o Termo de Consentimento Livre e Esclarecido. Depois de assinado iniciava-se a entrevista. No total foram 39 respondentes, sendo 19 profissionais, 9 amadores e 11 biprofissionais. Os respondentes são todos do sexo masculino e a idade dos mesmos varia de 21 a 47 anos.

Todos os 39 respondentes afirmaram que já sentiram ou sentem dores durante ou depois de terem tocado. Além disso, $84,62 \%$ destes músicos têm algum conhecido músico que já teve algum problema de saúde por conta das atividades desenvolvidas. Esse número chega à quase totalidade entre os profissionais. Esses dados deixam claro o quanto a prática musical está entremeada de casos de dores e lesões, por mais que 
raramente se fale a respeito. Outro dado relevante é que, apesar desse comportamento, chamado por Costa (2003) de cultura do silêncio, 41,03\% dos músicos respondentes chegaram a procurar um médico por conta dessas dores ou desconfortos e $51,28 \%$ já procuraram outros músicos para conversar a respeito.

De modo mais consistente, 9 músicos (23,08\% da amostra) declararam já ter sido impedidos de tocar por esses tipos de problemas e 7 (17,95\% da amostra) disseram ter tido lesões por conta da atividade musical. Estes dados tanto afirmam a grande presença desses problemas entre os músicos da amostra da pesquisa quanto corroboram com as demais pesquisas que apresentam as dores, desconfortos e lesões como muito comuns no meio musical. É importante ressaltar que alguns dos respondentes começavam a pesquisa relatando poucos problemas ou até mesmo negando-os e, no decorrer da mesma, começavam a se lembrar de situações ou identificar desconfortos presentes na prática e que até então passavam despercebidas ou eram vistas como normais. Essa falta de consciência corporal de alguns músicos, somada à questão da cultura do silêncio, leva a crer que os números reais de músicos com constrangimentos sejam ainda mais expressivos.

Destaca-se que, além dos prejuízos físicos, esses problemas acarretam também em consequências emocionais/psicológicas. Quando indagados sobre o que sentiriam se passassem por uma situação mais grave, onde tivessem que parar de tocar, os respondentes declararam, por exemplo, que seria triste (11), sentiriam-se frustrados (9), arrependidos/culpados (3), ficariam depressivos (4) ou que seria como se tivessem tirado uma parte da vida deles (4).

\subsection{Cultura da dedicação}

A cultura da dedicação parece existir, mas não de maneira extremada dentro da amostra estudada. Se, por um lado, a maioria dos respondentes concorda que os instrumentos são como parte do músico e merecem inteira dedicação do mesmo, que a música é algo sublime e que por isso merece qualquer tipo de sacrifício e que é melhor tocar sentindo um pouco de dor do que ter que parar de tocar, por outro, a maioria discorda que a dor seja a coisa a que tenha menos importância quando e estão tocando e discordam também com a questão de que as dores sentidas sejam indício de que se esteja progredindo tecnicamente, desmentindo a máxima do "no pain, no gain".

É interessante notar que os profissionais são os que mais concordam com a dedicação que se deve ter aos instrumentos e com os sacrifícios a serem feitos pela música. No entanto são os que parecem menos dispostos a tocar sentindo um pouco de dor e são os que mais discordam que seja atribuída pouca importância à dor na hora de tocar. As respostas obtidas nos questionários mostram os músicos profissionais mais dedicados às atividades musicais (como era de se esperar) ou até mesmo mais dependentes enquanto os amadores parecem encará-la mais como modo de se distrair ou esquecer os problemas.

Nas entrevistas, essa divisão, ora pendendo para o lado da dedicação, ora para uma consciência de que a atividade não deve trazer dores, também se mostra presente. No geral, a maioria (20 dos 39 respondentes) considera que a dor, de alguma forma, faz parte da atividade musical (apenas 11 discordam). Alguns consideram a dor normal na prática musical ou em qualquer outra atividade. 


\subsection{Emoções, sentimentos e estado de flow}

Com relação à ocorrência do estado de flow na prática musical, quase todas as afirmativas receberam avaliação favorável por pelo menos metade dos respondentes, algumas chegando a quase $100 \%$ de concordância. Das 22 afirmativas, houve apenas 2 exceções:

- A afirmativa "Quando estou tocando, me sinto em completa harmonia com tudo ao meu redor" recebeu apenas $46,15 \%$ de concordância e uma grande taxa de respostas nulas (38,46\%). As discordâncias, no entanto, foram poucas (15,38\%). Esse resultado possivelmente se deu por conta do conteúdo subjetivo e pouco concreto com relação ao que seria a "harmonia";

- A afirmativa "Às vezes me sinto insatisfeito quando tenho que tocar alguma música da qual não gosto" recebeu uma maioria de concordância (69,23\%), o que condiciona a satisfação do músico em tocar ao fato de estar tocando uma música que gosta. Isto pode ser mais recorrente entre músicos profissionais (já que tocam repertórios variados e sujeitos a diretrizes de empregadores) e é justamente nesse grupo que aparece a maior taxa de concordância $(84,21 \%)$.

Com esses dados, pode-se dizer que, nessa amostra, a atividade musical apresenta várias características próprias do flow como extrema concentração na atividade, perda da noção do tempo, feedback imediato, felicidade posterior à atividade etc. Contudo, isso não significa que o estado de flow sempre ocorra. Isso depende de fatores pessoais e situacionais. Pode ser que um determinado músico experimente isso enquanto outros não e que o mesmo músico experimente em apenas algumas situações. É inegável, no entanto, que a atividade musical, apresenta as condições típicas para a ocorrência desse estado. Algumas descrições feitas pelos músicos também são coerentes com descrições do estado de flow. Por exemplo:

Você esquece quando você tá empolgado, quando você tá feliz naquele momento ali, você quer animar o publico, você quer fazer o seu show, não importa se tacaram uma pedra em você, se seu dedo tá sangrando, quê que foi que aconteceu que enfim, a pessoa dá um jeito de fazer o show dele. Tanto é que uma vez eu caí do palco e eu tentei continuar tocando.

Outro respondente descreve, no contexto da prática musical, um comportamento descrito por Damásio (2004) de quando se foge de algum perigo e os mapas cerebrais e sentimentos não correspondem ao real estado do corpo:

Eu acho que quando você tá imerso numa coisa que você gosta muito de fazer, no caso a música, (...) você releva outras coisas. Eu acho que é uma coisa quase instintiva você dar pouca importância pra fatos como esses... Na verdade, parece que existe uma pré-consciência de que aquilo existe, que você vai sentir aquilo lá e que você tem que esquecer aquilo lá naquele momento. Acho que existe esse condicionamento que a gente mesmo faz.

Alguns falam ainda do perigo dessa espécie de anestesia provocada pelo cérebro, uma vez que pode fazer com que o músico se machuque sem perceber.

\subsection{Cultura do Cuidado}

Foi percebido na pesquisa que, apesar de muitos músicos terem noção do que devem fazer para evitar dores provenientes da prática musical, são poucos os que realmente levam a sério essa questão e realmente tem comportamentos preventivos. Essa falta de cuidado com o próprio organismo é notada pelos próprios respondentes, 
que falam da necessidade dos músicos (e outros indivíduos relacionados à prática musical) darem mais atenção a essas questões, de modo que a prática seja mais saudável e não se espere algum problema de saúde para começar a se cuidar:

(...)as dores são consequência de uma atividade errada, desde a parte que a gente aprende a tocar da aula, o máximo que o professor fala é que você alonga... alongamento dos dedos, (...) mas não tem aquele cuidado, a gente nunca tem cuidado do início, lá que começa a tocar, (...) então eu acho que o principal seja essa falta de cultura mesmo, do músico de tomar cuidado com o corpo enquanto é tempo.

Esse respondente faz uso de duas palavras-chave: cultura e cuidado. E é justamente uma cultura do cuidado que deve ser implantada no meio musical, tomando lugar das já citadas cultura do silêncio e da dedicação. O silêncio só camufla os problemas enfrentados pelos músicos, não os soluciona, e a dedicação pode ser boa, desde que acompanhada de um cuidado constante por parte de músicos e outros profissionais que auxiliem a tornar a prática mais saudável. Para finalizar, destaca-se um trecho de outro respondente que reforça essa necessidade de cuidado:

(...) dificilmente as pessoas tratam desse assunto e o próprio musico, às vezes, ele se negligencia sobre isso...se dedica ao ofício, ofício, ofício, mas esquece dele...porque quem tá ali, no caso o músico, espero que continue assim, é um ser humano, não é uma maquina...e até as próprias máquinas precisam de lubrificação, de cuidado e coisas semelhantes.

\section{CONCLUSÕES E DESDOBRAMENTOS}

A presente pesquisa objetivou esclarecer alguns pontos relacionados ao tema dos constrangimentos provenientes da prática musical, principalmente no que diz respeito às emoções e sentimentos relacionados a essa prática e como esses elementos subjetivos podem interferir na percepção da dor pelos músicos. No entanto, trata-se de um tema complexo e percebe-se que ainda há muito a ser esclarecido. Deste modo, são necessárias ainda muitas pesquisas para que se chegue a soluções mais concretas que reduzam os riscos à saúde dos músicos e não prejudique o seu desempenho artístico. Tem-se que os próprios dados gerados na coleta de dados deste trabalho podem ser utilizados em posteriores análises - mais detalhadas ou procurando-se relacionar outras variáveis. Além disso, enumera-se aqui, alguns pontos que podem ser investigados em futuras pesquisas:

- O estudo mais detalhado do estado de flow entre os músicos, que envolva o relato de como os mesmos se sentem durante o exercício das atividades;

- Aplicação de questionários apenas com respostas fechadas sobre o flow, que possibilitem a aplicação com um número maior de indivíduos e possibilite chegar a conclusões melhor embasadas;

- O aprimoramento do LeDOS - Music, detectando pontos onde pode-se melhorar o processo de levantamento de dados;

- A execução de intervenções ergonomizadoras em instrumentos musicais e postos de trabalhos de músicos de modo que se preservem as características estéticas pretendidas pelos músicos, facilitando o processo de aceitação pelos usuários.

\section{REFERÊNCIAS}

BLANNING, Tim. 0 triunfo da música: A ascensão dos compositores, dos músicos e de sua arte. São Paulo: Companhia das Letras, 2011. 
BRANDFONBRENER, Alice G. Musculoskeletal problems of instrumental musicians. Hand Clinics, v.19, n.2, p.231-239, 2003.

CHAN, Rachel F.M. et al. Self-perceived exertion level and objective evaluation of neuromuscular fatigue in a training session of orchestral violin players. Applied

Ergonomics, v.31, p.335-341, 2000.

COSTA, Cristina Porto. Quando tocar dói: Análise ergonômica da atividade de violistas de orquestra. Brasília: s.ed., 2003. Disponível em:

<http://vsites.unb.br/ip/labergo/sitenovo/dissertacoes/OrientJulia/CristinaP/cporto.p df>

CSIKSZENTMIHALYI, Mihaly. Go with the flow: Wired, set 1996. Entrevista concedida a John Geirland. Disponível em: <http://www.wired.com/wired/archive/4.09/czik.html> Acesso em: 17 de abril de 2012.

Finding flow: the psychology of engagement with everyday life. New York:

Perseus books, 1997.

DAMÁSIO, António. Em busca de Espinosa: prazer e dor na ciência dos sentimentos.

São Paulo: Companhia das Letras, 2004.

DAUM, Miriam C. Musculoskeletal Problems in Musicians. Center for Safety in the Arts, 1988. Disponível em: <

http://www.uic.edu/sph/glakes/harts1/HARTS_library/musicms.txt> Acesso em: 10 mar. 2012.

DOMMERHOLT, Jan. Performing arts medicine - Instrumentalist musicians Part I General considerations. Journal of bodywork and movement therapies, v. 13, p.311319, 2009.

FRANK, Annemarie; VON MÜLHEN, Carlos Alberto. Queixas Musculoesqueléticas em Músicos: Prevalência e Fatores de Risco. Revista Brasileira de Reumatologia, v. 47, n. 3, p. 188-196, mai/jun, 2007.

HAIR JR., Joseph F. et al. Fundamentos de pesquisa de marketing. Porto Alegre: Bookman, 2010.

MED, Bohumil. Vida de Músico não é fácil: Pequeno manual de sobrevivência na selva musical - Dicas do Bohumil. Brasília: MusiMed Edições Musicais, 2004)

POORE, G. Vivian. Clinical Lecture: On certain conditions of the hand and arm which interfere with the performance of professional acts, especially piano-playing. The British Medical Journal. p.441-444, fev 1887.

QUARRIER, Nicholas F. Performing Arts Medicine: The Musical Athlete. Journal of Orthopaedic \& Sports Physical Therapy, v. 17, n. 2, fev, 1993.

SOUZA, Rodrigo Alcântara; MONT'ALVÃO, Claudia Renata. Constrangimentos ergonômicos e teoria de flow na prática musical. In: 10.0 P\&D Design - Congresso Brasileiro de Pesquisa e Desenvolvimento em Design, 2012, São Luiz, MA. Anais do X Congresso Brasileiro de Pesquisa e Desenvolvimento em Design. São Luiz, MA, EDUFMA, 2012.

SUBTIL, Marina Medici. Fisioterapia para músicos. Vitória: Oficina de Letras, 2009. ZAZA, Christine; CHARLES, Cathy; MUSZYNSKI, Alicja. The meaning of playing-related musculoskeletal disorders to classical musicians. Social Science \& Medicine, v. 47, n. 12, p. 2013-2023, 1998. 